\title{
Lead-Bismuth and Lead as Coolants for Fast Reactors
}

\author{
G. I. Toshinsky ${ }^{1,2^{*}}$, A. V. Dedul ${ }^{1}$, O. G. Komlev ${ }^{1}$, A. V. Kondaurov ${ }^{1}$, V. V. Petrochenko ${ }^{1}$ \\ ${ }^{1}$ JSC “AKME-Engineering”, Moscow, Russia \\ ${ }^{2}$ JSC “SSC RF-IPPE”, Obninsk, Kaluga, Russia \\ Email: ^toshinsky@ippe.ru
}

How to cite this paper: Toshinsky, G.I., Dedul, A.V., Komlev, O.G., Kondaurov, A.V. and Petrochenko, V.V. (2020) Lead-Bismuth and Lead as Coolants for Fast Reactors. World Journal of Nuclear Science and Technology, 10, 65-75.

https://doi.org/10.4236/wjnst.2020.102007

Received: January 5, 2020

Accepted: February 14, 2020

Published: February 17, 2020

Copyright (c) 2020 by author(s) and Scientific Research Publishing Inc. This work is licensed under the Creative Commons Attribution International License (CC BY 4.0).

http://creativecommons.org/licenses/by/4.0/

\section{Open Access}

\begin{abstract}
Fast reactors used lead-bismuth eutectic (LBE) and lead as coolants possess very high level of inherent self-protection and passive safety against severe accident. So, population radiophobia can be overcome. That type of reactors can be simultaneously more safely and more cheaply. As all other coolants, $\mathrm{LBE}$ and lead coolant (LC) possess the certain virtues and shortcomings. The presented report includes the comparative analysis of characteristic properties of those coolants, their impact on reactor safety, reliability and operating characteristics. The conclusion is made about promising usage of FRs with these coolants in future NP after the experience in operating of the prototypes of such reactors has been obtained.
\end{abstract}

\section{Keywords}

SVBR-100, Fast Reactor, Lead-Bismuth Coolant, Lead Coolant, Nuclear Power Plant, Inherent Self-Protection, Melting Point, ${ }^{210}$ Po, Bismuth Recourses

\section{Introduction}

To provide sustainable development of the future nuclear power (NP), it must be large-scale one. It is possible for use of fast reactors (FR), which breeding ratio (BR) is equal or exceeds one, operating in the closed nuclear fuel cycle (NFC). That makes it possible to involve ${ }^{238} \mathrm{U}$ (widespread heavy uranium isotope) instead of ${ }^{235} \mathrm{U}$ (rare light uranium isotope) in generation of electric power at the NPP. Due to the highlighted fact, the source of raw fuel for the NP can be extended approximately one hundred times more thus providing the people with energy for many thousands of years without carbon release into the atmosphere and consumption of oxygen. To realize that opportunity, the FRs must operate 
in the closed NFC with recycling of built-up plutonium. At the same time, the future large-scale NP must be competitive with fossil power plants (FPPs) and must deterministically eliminate the severe accidents requiring population evacuation. At present, in the world there are no nuclear power technologies (NPTs), which can meet all the highlighted requirements. However, now such NPTs are developed in many countries.

Along with that, to this day the FRs are not developed widely. Moreover, at present the time for their economically expedient implementation in the NP is being postponed. For instance, in the USA, where the park of thermal reactors (TR) is the largest (about $100 \mathrm{GWe}$ ), it is not planned to implement FRs in the current century due to considerable increase of the natural uranium cost that can result in loss in competitiveness of the NPPs based on TRs with FPPs.

The main reason is that FRs are much more expensive than TRs. That is conditioned by the fact that everywhere the sodium was selected as coolant as possessing the best heat-transfer properties, which allowed providing of intensive heat removal in the core and high rate of excess plutonium buildup (short plutonium doubling time). The highlighted requirement to FRs was a determining factor in the last seventies due to existing conditions, when the resources of cheap natural uranium were explored in low scales and the pace of electric power development and especially NP development was high. The required doubling time of plutonium (and consequently the time of doubling of the number of NPP power units) was ten years and less.

The lower economical parameters of those FRs associated with additional expenditures for safety caused by natural properties of sodium, namely: extremely high chemical activity while contacting with water and air that is possible in accidental situations. Those additional expenditures are caused by the necessity to provide the following: 1) intermediate sodium circuit between the radioactive sodium primary circuit and steam-water circuit, 2) casing of sodium pipelines, 3) more complicated technology of SNF handling prior to installation of the unloaded fuel sub-assemblies (FSA) in the cooling water pool, 4) special measures on fire-prevention and hydrogen safety. In the result, the future large-scale NP is necessarily planned as a dual-component one, namely: in the closed NFC the more expensive sodium fast reactors (SFR) "are feeding" the cheaper TRs by their excess plutonium.

At present in most countries, where development of NP is realized, there are no external factors highlighted above. For that reason, use of sodium in FRs is not without alternatives. Use of heavy liquid metal coolants (HLMCs) as FR coolants, which heat-transfer properties are much worse as compared with those of sodium, does not allow obtaining of short plutonium doubling time. However, due to the natural properties of chemical inertness and extremely high boiling point, it forms the backgrounds for construction of FRs with a very high level of inherent self-protection that deterministically eliminates severe accidents requiring the population evacuation (the more detailed the consideration of that question was given in Paper (Ref. [1]) for LBE cooled FR). At this point, the FRs are 
not burdened with additional expenditures for safety required for both, water cooled TRs and sodium cooled FRs. Due to that fact, after demonstration of that technology it is possible to consider one-component structure of the future large-scale NP based on FRs with HLMCs as an option. More detail use HLMC in FRs is considered in Paper (Ref. [2]).

In this case the conflict between the increasing safety requirements, unavoidable in the future, and economics requirements can be eliminated. The highlighted conflict that is peculiar to reactor facilities (RF), which use coolants with large amounts of accumulated potential energy (compression energy, chemical energy), is as follows: rise in safety requirements due to expected significant increase of NPP power-units in future is inevitably resulting in growth of the number of safety systems and their power capacity, increase of the number of defense barriers. Thus, the capital and operating costs are growing and the NPP competitiveness is lowering. For comparison, in water coolant, sodium coolant and heavy liquid metal coolants the values of accumulated potential energy (compression and chemical energy) are 20, 10 and zero GJ/m³ correspondingly (Ref. [3]). Use of HLMC is forming the backgrounds for simplification of the RF design due to elimination of the certain safety systems required in the RFs with other coolants. Thus, it is possible to construct NPPs on the basis of FRs with HLMC, which aren't only safer, but cheaper, as compared with NPPs based on traditional type reactors.

The Global Agreement on Climate, that was accepted by 196 parties on 12. 12 . 2015 and signed on 22. 04. 2016 at UN Climate Change Conference held in Paris and purposed to replace the Kyoto Protocol, will come into force in 2021 and does not specify the concrete ways of lowering of carbon exhausts into the atmosphere. It does not provide establishment of the mandatory tax on carbon exhaust as well. Moreover, the nuclear option is not provided in the Agreement, and that is conditioned mainly by radiophobia of the population, whose opinion is accounted by politicians. Along with that, large-scale development of the NP provides the opportunity of considerable lowering of carbon released into the atmosphere.

Those are the reasons, which provide the necessity for future changeover to the reactors with the considerably higher level of inherent self-protection. In such reactors the severe accidents requiring the population evacuation must be deterministically eliminated, i.e. the reasons to cause severe accidents will be excluded. RFs with HLMC will make it possible to overcome the population radiophobia that has grown again after the accident occurred at NPP Fukushima 1. It is much easier to convince the population in the NPP safety if it is provided by nature laws (e.g. absence of pressure in the reactor, lack of hydrogen release assure that explosion cannot occur and so on), which eliminate the internal reasons for those consequences. It is more clearly understood for the people, who consider the events on the basis of their own experience, but not on the results of probabilistic safety analyses. 


\section{Natural Properties of Lead-Bismuth and Lead Coolants and Their Impact on Fast Reactor Characteristics}

\subsection{LBE and LC Common Properties}

1) Extremely high boiling point, namely: $1670^{\circ} \mathrm{C}$ and $1740^{\circ} \mathrm{C}$ correspondingly for LBE and LC. Thus, the necessity to provide high pressure in the primary circuit and heat-removal crisis are eliminated. That eliminates also the opportunity of HLMC loss (LOCA) with core melting. Besides, that exclude high pressure radioactivity release and allow designing the protective shall only against of external impact (aircraft fall);

2) Chemical inertness while contacting with air and water. So, there are not reasons for forming of hydrogen in all accidental situations, reactor explosion and fires. HLMC chemical inertness regarding to water is eliminating the necessity in the intermediate circuit. To localize the events with leak in SG tubes, the steam condensers are provided in the primary circuit gas system. In an event of their failure it is provided that steam-gas mixture is passively discharged to the bubbler via the rupture membranes (bursting disk). The hydraulic diagram of HLMC circulation in the reactor is realizing effective gravitational separation of steam bubbles on the HLMC free level under the reactor lid. Experience of operating the LBE cooled reactors at nuclear submarines (NS) has revealed that in an event of small leak in the SG (up to $10 \mathrm{~kg} / \mathrm{h}$ ) there is no necessity in immediate RF shutdown (Ref. [4]);

3) Coolant compatibility with oxide fuel is eliminating the event that the accidental situation with untightness in the fuel element cladding is developing in the event with direct contact fuel and coolant with release of radioactivity in coolant how it happens quickly in PWRs and SFRs.

(These three properties assure a very high level of inherent self-protection allowing elimination of the certain safety systems and cheapening of the NPP);

4) Very low moderation of neutrons on lead and bismuth nuclei as compared with FRs cooled by other coolants. That results in heightening of efficiency of nuclear transmutation of minor actinides (MA), which possess the threshold dependence of microscopic fission cross-sections on neutron energy. As a result, while FRs are operating in the closed NFC, in a certain time the concentration of MA nuclei (neptunium, americium, curium) upon their recycling is reaching saturation as the rate of their loss caused by fission becomes equal to the rate of their formation. At that point, the specific radioactivity of MA (counting on one GW-y of produced power) will decrease with increase of cumulative energy-generating (Ref. [5]). So, it makes easier finding the solution to the problem of MA management at the back-end stage of the NFC, including the accelerated driven system (ADS), because long-lived isotopes of MA determine the radiotoxicity of the waste, which should be sent to the final burial. The harder neutron spectrum is also leading to diminishing of the positive constituent of void reactivity effect by making it negative for small power FRs with high neutron leakage. And this is important for safety; 
5) To provide corrosion resistance of steels, in both coolants it is required to maintain the concentration of dissolved in coolant oxygen within the specified limits for the purpose to provide thermo-dynamical stability of protective oxide cover on the steel surface, and use of relevant devices for maintenance of coolant quality. Today these problems resolved successfully (Ref. [6]);

6) High density of HLMC that requires to reduce the flow velocity for the purpose to prevent high consumption of energy for coolant circulation, use of special seismic insulation against the earthquake, especially for large unit capacity reactors, and tacking into account buoyancy steel and fuel sub-assemblies in the coolant;

7) Comparatively low thermal conductivity of HLMC that restricts the opportunity to achieve high heat flux from the surface of fuel element claddings.

The last two properties exclude obtaining of high core power density and short plutonium doubling time as in the FR with sodium coolant.

\subsection{Differing Properties and Characteristics of LBE and LC}

\subsubsection{Melting Point}

The melting point of $\mathrm{LBE}$ is much lower $\left(124^{\circ} \mathrm{C}\right)$ as compared with that of $\mathrm{LC}$ $\left(327^{\circ} \mathrm{C}\right)$. It results in the following distinctions in RF characteristics:

- Considerable widening of the operating temperature range for LBE as compared with that for LC. It means that at the core outlet the temperature of both coolants must be limited by the same value $\left(500^{\circ} \mathrm{C}-550^{\circ} \mathrm{C}\right)$ determined by corrosion resistance of steels, the coolant temperature at the core inlet for LC must be considerably higher than that for LBE. It is necessary for the purpose to eliminate LC solidifying in normal operation mode, in transient modes, modes of start-up and shut-down cooling. Under the same power, reduction of LC heating in the core can be only achieved due to heightening of flow rate. Under corresponding increase of LC velocity, it will lead to increase in pump capacity as cubic dependence on flow rate. Provided the LC velocity is maintained as that of LBE, it results in increase of the core flow cross section that can be obtained by growth of its diameter or by diminishing of volume fraction of fuel. In both cases, under use of LC the RF technical and economical characteristics will be deteriorated;

- To eliminate LC "freezing" in the steam generator (SG), the higher temperature of its melting requires heightening of the temperature of feeding water supplied in the SG that results in the necessity to rise the steam pressure and, correspondingly, boiling temperature of water, as well as to inclusion in the secondary circuit hydraulic diagram the additional heater for feeding water heating to the temperature exceeding the melting point of lead $\left(327^{\circ} \mathrm{C}\right)$. That raises the RF cost, complicates it, increases the power consumption for own needs under slight increase of thermo-dynamical cycle efficiency;

- The necessity to maintain the LC temperature at a level close to $400^{\circ} \mathrm{C}$ eliminates performance of repair works, replacement of the equipment and RF servicing without use of the robotized equipment. 


\subsubsection{Volume Change while LBE and LC Melting}

Experience of operating the LBE cooled RFs at nuclear submarines has revealed that unintended "freezing" of coolant in the RF cannot be excluded. For the purpose to maintain the equipment operability, it results in the necessity of safe heating and "unfreezing" of coolant in the RF (Ref. [7]).

In accordance with reference (Ref. [6]), the LBE volume does not change in the process of melting. After LBE "unfreezing", this fact provided the operable state of the equipment in the LBE cooled RF including the operability of the whole primary circuit in the RF of first experimental NS K-27 of Project 645 after several years of "frozen" state. It was also favored by comparatively low range of temperatures from $20^{\circ} \mathrm{C}$ to LBE melting point of $123.5^{\circ} \mathrm{C}$ while RF heating when mechanical stresses in the equipment arise because of difference in thermal expansion factors of LBE and steel, that is, stresses in the structures did not lead to their deformation. One more property of LBE should be highlighted, namely: slow spontaneous increasing of LBE volume in the solid stage that is approximately $0.5 \%$ for two months and is conditioned by changes in crystal structure (Ref. [7]). In specially performed experiments the slow "self-extrusion" of LBE through the small hole was observed. However, low hardness and high plasticity of the solid LBE excluded development of damages in the equipment.

The possibility of safe "freezing-unfreezing" of LBE while maintaining the operability of the equipment is also important to ensure the transportation of modular small-power RF with loaded fuel and solid LBE (nuclear "battery") and long-term storage of SNF (Ref. [8]).

At the same time, when melting, the lead volume is increased by $3.7 \%$ (Ref. [6]). The range of temperature change in the process of heating from $20^{\circ} \mathrm{C}$ to $\mathrm{LC}$ melting temperature of $327^{\circ} \mathrm{C}$ is much higher than that for LBE. These factors should be accounted in the course of mastering the LC "unfreezing" mode, bearing in mind that shrinkage holes forming in the process of lead solidifying will be formed in some points of the primary circuit, and volume increase in the process of melting will occur in other points of the circuit.

\subsubsection{Generating of Alpha-Active Radionuclide ${ }^{210} \mathrm{Po}$}

In LBE this parameter is much worse than that in LC. Rate of ${ }^{210} \mathrm{Po}$ generating in LBE is $10^{4}$ times more than that in LC.

In normal operating conditions the LBE polonium activity is not shown, though it is a source of potential radiation hazard that must be accounted while developing and operating the NPP based on LBE cooled RFs. Radiological hazard of ${ }^{210} \mathrm{Po}$ is revealed when LBE or gas contacting with LBE is penetrated in servicing rooms. Such events occurred in accidents and repairs of the NS reactor facility and ground-based facilities-prototypes in the period of their mastering.

As operating experience of the NS RF has revealed, after reducing of temperature and solidifying of the spilled LBE, release of ${ }^{210} \mathrm{Po}$ aerosols and air radioactivity decrease sharply in accordance with thermodynamics laws. Fast solidifying of spilled LBE restricts the area of radioactive contamination and makes possible removal of the spilled LBE in a form of solid radioactive waste. 
In an event of accidental loss of tightness in the primary circuit, low concentration of polonium in $\operatorname{LBE}\left(10^{-6} \mathrm{~mol}\right)$ and formation of thermodynamically stable chemical compound of polonium with lead set conditions for low concentration of ${ }^{210}$ Po in air.

To perform repair and maintenance works on the contaminated equipment, works on removal of spilled coolant (approximately 20 tons at 27/VT Facility), the measures on individual and collective protection of the personnel (such as respirators, protecting clothes, organization of ventilation) were developed. Moreover, the following methods were developed: methods of decontamination of the equipment, fixing of activity on surfaces, techniques of performance of repair and maintenance works, which reduced the risk of penetration of ${ }^{210} \mathrm{Po}$ in hazardous amounts into the human organism and on the skin.

The personnel, who took part in those works, was subjected to periodic examinations, and based on multiple radiometric analysis of biological tests of the personnel (both military and civilians), the absence of events with presence of incorporated polonium in human organisms over the permissible levels was established (Ref. [9]). That fact validated a high efficiency of used individual and collective protection measures, the right option for the technology and correct organization of repair and maintenance works. It was also promoted by comparatively quick polonium washout from the human organism resulted from metabolic processes (effective period of semi-ejection was approximately 30 days) and very low molar concentration of polonium in LBE that lessened its volatility as compared with pure polonium. All the more, it is right for the integral design $\mathrm{RF}$ with protective casing that eliminates the opportunity of LBE leaks.

In Paper (Ref. [10]) published in the USA the data on retrospective analysis of mortality among the personnel who were dealt with released ${ }^{210}$ Po on Mound Facility in 1944-1972. They were examined for ${ }^{210}$ Po internal irradiation. Medical protocols of bioassays (over 160,000 bioprobes) were analyzed for the group of 4402 white men dealt with ${ }^{210}$ Po during that period (104,326 man.years) and these data were compared with the official data on death reasons for 987 men from this group during the period till January of 1984 .

The statistical data on mortality among this group was also compared with the corresponding data for two reference groups (average over the USA and over Ohio State). The conclusion was made that there was no correlation between polonium internal irradiation doses up to $1 \mathrm{~Sv}(100 \mathrm{rem})$ and mortality level caused by malignant formations. Practically, all observed trends, which characterized death-rate caused by cancer in the studied group, were negative, i.e. mortality in the examined group was even less than in two monitored groups.

On carrying out the investigations and examining the obtained experience, the American and Japanese experts have come to conclusion that formation of polonium in LBE cannot impede LBE use in future NP (Ref. [11], [12]). This is verified by the fact that works on development of LBE cooled fast reactors are realized in certain countries (namely: SVBR-100 in Russia, MYRRHA in Belgium, CLEAR in Chinese People's Republic, etc.). 
It does not consider the use of LBE in ADS when, as a result of nuclear spallation reactions as a result of direct interaction of high-energy protons and neutrons with lead and bismuth nuclei, a significantly larger number of different polonium isotopes and more dangerous radionuclides $\left({ }^{206} \mathrm{Hg}\right)$ are formed. At high energies of protons and neutrons as in the ADS, the difference between cross-section of lead and bismuth is insignificant.

\subsubsection{Lead and Bismuth Resources, Production Scales and Costs}

Resources, scale of production and cost characteristics for LC are better than those for LBE. Lead is widespread in more amounts in nature, its explored resources and production scales do not limit LC use in NP, the cost of lead is lower than that of bismuth.

Up to present, the available data on explored bismuth resources has not allowed LBE application in the large-scale NP. However, not long ago the specialized Rosatom enterprises, namely: JSC "Atompedmetzoloto" and VNIPI promtehnologii have realized technical and economical investigations into the opportunity to organize large-capacity bismuth production in Russia and assessment of bismuth resources in the Commonwealth of Independent States (CIS). Their results have revealed that in Russia on the basis of explored bismuth deposits in the only Chita region, it is possible to realize profit-making production of bismuth in quantities, which are sufficient enough to put in operation approximately 50 GWe of NPPs with LBE cooled FRs with a pace of 1 GWe per year (Ref. [13]). Moreover, there are large bismuth resources in the North Caucasus. It is possible to put in operation $\sim 250$ GWe using the bismuth mines of Kazakhstan. The assessments made by Japanese experts have shown that available bismuth resources are approximately 5 million tons (Ref. [12]).

It should be highlighted that in compliance with general geological and economical laws, the quantity of mineral resources increases proportionally to the squared cost that the consumer is ready to pay for those resources.

For the current world's costs of bismuth, its contribution to the capital costs for construction of the NPP based on FRs does not exceed several percent shares. For that reason, the technical and economical parameters of the NPP will not be noticeably worth even when the bismuth cost increases several times. In addition, lead and bismuth can be used to produce LBE without deep purification of lead from bismuth and bismuth from lead, which reduces the cost of LBE. After decommissioning of the RF, LBE can be used repeatedly many times in the new RFs by refining, if it is necessary. In the future when the cheap bismuth resources have been expired, it will be possible to change over to lead-bismuth alloy of a non-eutectic composition with reduced bismuth content and higher boiling point. For example, when bismuth content in the alloy is reduced to $10 \%$ (5.5 times), the melting point is increasing from $123.5^{\circ} \mathrm{C}$ to $250^{\circ} \mathrm{C}$ that is considerably lower than the melting point of pure lead $\left(\sim 327^{\circ} \mathrm{C}\right)$ and does not make excessive difficulties for RF operation. 


\subsubsection{Degree of LBE and LC Mastering}

As for this parameter that is sometimes named technological readiness level (TRL), the LBE much outshines the LC as there is many-year experience of operating the LBE cooled reactors at Russian NSs and ground-based facilities-prototypes, which operation in all modes is approximately 80 reactor-years. Development of RFs with LBC was realized in conditions of absence of necessary knowledge and experience. Moreover, the fixed directive terms of work completion practically eliminated the opportunity for performance of related scientific and research works that caused a number of failures at the stage of mastering of that technology.

Of course, this operating experience, which at the initial mastering stage was followed by different accidents caused by absence of necessary knowledge and experience (Ref. [4]), cannot be impressive enough for the civilian RFs.

Along with that, in the part of RF maintenance, equipment repair and replacement, SNF refueling and storage, modes of coolant technology, providing of radiation safety while operating with the polonium contaminated equipment, LBE "unfreezing" modes, the obtained experience is sufficiently representative.

For that reason, construction of LBE cooled RFs is associated with noticeably less technical and financial risks in compare with lead cooled FRs.

\section{Conclusions}

1) In the RFs with LBE and LC the amount of accumulated potential energy in coolants is minimal that makes possible realization of inherent self-protection and passive safety properties to a maximal extent and elimination of the reasons of severe accidents requiring the population evacuation. Such properties of RFs with LBE and LC will make it possible to overcome the population radiophobia that has grown again after the accident occurred at NPP Fukushima 1. That is very important for large-scale and sustainable development of NP. As the third Director General of the IAEA Hans Blix said, "If the accident occurs somewhere, it is an accident everywhere." Therefore, chain of safety of large-scale future NP shouldn't have weak links.

2) As all other coolants, LBE and LC possess advantages and drawbacks considered in Section 2. Their impacts on NPP technical and economical characteristics, safety and reliability are different. The main common properties of LBE and LC are very high boiling point and chemical inertness while contacting with air and water. It is these properties assure a very high level of inherent self-protection allowing elimination of the certain safety systems and cheapening of the NPP. The main different property of these coolants is higher melting point of lead, which will make operation lead cooled FRs more difficult.

3) It is not possible to give preference to any coolant without construction and obtaining of real operating experience for experimental (demonstrational) prototypes of NPP RFs with lead-bismuth and lead coolants. Along with that, for LBE cooled RF the technical and financial risks, which follow mastering of each innovative technology, will be much less due to having experience of LBE cooled reactors, than those for RF with lead coolant that has no experience of application in the reactors. 


\section{Acknowledgements}

The authors would like to thank Svetlana Budarina, the specialist of Joint Stock Company "Scientific Technical Center Diaprom", for assistance in preparation of the present paper.

\section{Conflicts of Interest}

The authors declare no conflicts of interest regarding the publication of this paper.

\section{References}

[1] Toshinsky, G.I., Komlev, O.G. and Dedul, A.V. (2019) Inherent Self-Protection, Passive Safety and Competitiveness of Small Power Modular Fast Reactor SVBR-100. Paper ID-4 Technical Meeting on the Benefits and Challenges of Fast Reactors of the SMR Type, Milan, Italy, 24-27 September 2019, to be published in IAEA Proceeding of Technical Meeting.

[2] Toshinsky, G.I. (n.d.) Heavy Liquid Metal Coolants in Nuclear Power. To be published in OSP Journal of Nuclear Science.

[3] Toshinsky, G.I., Komlev, O.G., Tormyshev, I.V. and Petrochenko, V.V. (2013) Effect of Potential Energy Stored in Reactor Facility Coolant on NPP Safety and Economic Parameters. World Journal of Nuclear Science and Technology, 3, 59-64. https://doi.org/10.4236/wjnst.2013.32010

[4] Toshinsky, G.I., Stepanov, V.S., Nikitin, L.B., et al. (2016) The Analysis of Operating Experience of Reactor Installations Using Lead-Bismuth Coolant and Accidents Happened. In: Toshinskii, G., Ed., Lead-Bismuth Cooled Fast Reactors. Collection of Selected Articles and Papers. LAMBERT Academic Publishing, Riga, 42-54.

[5] Toshinsky, G.I. and Petrochenko, V.V. (2012) Modular Lead-Bismuth Fast Reactors in Nuclear Power. Proc. of Sustainability 2012, 4, 2293-2316. https://doi.org/10.3390/su4092293

[6] OECD-NEA (2015) Handbook on Lead-Bismuth Eutectic Alloy and Lead Properties, Materials Compatibility, Thermal-Hydraulics and Technologies. 2015 Edition.

[7] Pylchenkov, E.H. (1999) The Issue of Freezing-Defreezing Lead-Bismuth Liquid Metal Coolant in Reactor Installations' Circuits. Proceedings of $1^{\text {st }}$ International Conference on Heavy-Liquid Metal Coolants in Nuclear Technologies (HLMC-98), Obninsk, Russia, October 5-9 1998, 110-119.

[8] Toshinsky, G.I., Grigoriev, S.A., Dedul, A.V., Komlev, O.G. and Tormyshev. I.V. (2019) Safe Controlled Storage of SVBR-100 Spent Nuclear Fuel in the Extended-Range Future. World Journal of Nuclear Science and Technology, 9, 127-139. https://doi.org/10.4236/wjnst.2019.93009

[9] Pankratov, D.V., Yefimov, E.I., Toshinsky, G.I. and Ryabaya, L.D. (2016) Analysis of Polonium Danger in Nuclear Power Installations with Lead-Bismuth Coolant. In: Toshinskii, G., Ed., Lead-Bismuth Cooled Fast Reactors. Collection of Selected Articles and Papers. LAMBERT Academic Publishing, Riga, 125-138.

[10] Wiggs, L.D., Cox-DeVore, C.A. and Voelz, G.L. (1991) Mortality among a Cohort of Workers Monitored for Po-210 Exposure: 1944-1972. Health Physics, 61, 71-76. https://doi.org/10.1097/00004032-199107000-00007

[11] Tupper, R.B., Minuskin, B., Peters, F.E. and Kardos, Z.L. (1991) Polonium Hazard Associated with Lead-Bismuth Used as a Reactor Coolant. Proc. of International Con- 
ference on Fast Reactors and Related Fuel Cycles. Current Status and Innovations Leading to Promising Plants, Kyoto, Japan, 28 October-1 November 1991.

[12] Ichimiya, M.A. (2000) Conceptual Design Study on Various Types of HLMC Fast Reactor Plant. Lead-Bismuth Technology International Meeting, OEC/JNC/Japan, 12-14 December 2000.

[13] Toshinsky, G.I. and Martynov, P.N. (2012) Large-Scale Use of Bismuth in Future Nuclear Power. In Bismuth: Characteristics, Production and Applications. Chapter 3, Nova Science Publishers, New York, 95-122.

\section{Abbreviation}

ADS: Accelerated Driven System

BR: Breeding Ratio

CIS: Commonwealth of Independent States

FPP: Fossil Power Plant

FR: Fast Reactor

FSA: Fuel Sub-Assembly

HLMC: Heavy Liquid Metal Coolant

IAEA: International Atomic Energy Agency

LBE: Lead-Bismuth Eutectic

LC: Lead Coolant

LCOE: Levelized Cost of Energy

MA: Minor Actinides

NFC: Nuclear Fuel Cycle

NP: Nuclear Power

NPP: Nuclear Power Plant

NPT: Nuclear Power Technology

NS: Nuclear Submarine

PSA: Probabilistic Analysis Method

RF: Reactor Facility

SFR: Sodium Fast Reactor

SG: Steam Generator

SNF: Spent Nuclear Fuel

SVBR: Lead-Bismuth Cooled Fast Reactor

TR: Thermal Reactor

TRL: Technological Readiness Level 